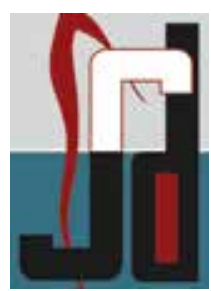

GASE REPORT

\title{
Low Flow Venous Malformation of the Buccal Mucosa Treated by Surgical Excision - A Rare Case Report
}

Sathyanarayanan.R ${ }^{1}$, Suresh. $V^{2}$, Venugopalan. $V^{3}$, Deepika. $S^{4}$

\begin{abstract}
Low flow venous malformations are characteristic lesions with unique presenting features. The most common sites of occurrence are the cheek and the ear in the midface region. Most centres recommend sclerotherapy as the first line of treatment for low flow vascular malformations. We report a case of low flow vascular malformation in the buccal mucosa treated successfully by wide excision and reconstructed with buccal pad of fat.

Case report: A 26 year old patient reported to our hospital with a painless swelling in the buccal mucosa. Under IV sedation patient underwent angiography via the femoral artery which showed no abnormal feeding vessels or draining veins. The lesion was treated by wide excision including the surrounding nidi, which was followed by reconstruction with buccal fat pad under general anaesthesia. The patient was followed up regularly and there was good take at recipient site and also there was no evidence of recurrence.
\end{abstract}

Conclusion: Low flow venous malformations can be managed by surgical excision alone if there is no feeder vessel or very minimal uptake of the dye by a feeder vessel with the combined effects of a surgeon and vascular radiologist.

Keywords: surgical procedure, reconstructive, fat pad, arteriovenous malformation

\section{Introduction:}

Low flow venous malformations falling under slow flow vascular malformations occur due to defective vascular development and they do not regress spontaneously and often cause symptoms. Intramucosal injection with sclerosing agents is now considered to be the first line of invasive therapy. Clinical evaluation includes a medical history, physical examination and imaging and angiography to locate the feeder vessel ${ }^{[1,2]}$. Fast flow vascular malformations can be differentiated from slow flow vascular malformations by the presence of increased ipsilateral pulses, palpable pulsations or thrill, and increased skin or mucosal temperatures which are absent in slow low flow vascular malformations. The size of this malformation is increased as blood is pooled from the normal circulation through a low resistance system created by the nidus, the aberrant arteriovenous network at the centre ${ }^{[3]}$. We report an uncommon case of one in the buccal mucosa with atypical features and negligible intraoperative bleeding during excision followed by reconstruction with buccal fat pad. The patient underwent femoral angiography for locating the feeder vessel. All the vessels in the head and neck region were checked (facial, internal, external carotid and vertebral arteries)

\section{Case report:}

A 26 year old patient reported to our hospital with a painless swelling in the buccal mucosa which was present for time duration of one year. The colour of the mucosa was reddish extending anteriorly $1 \mathrm{~cm}$ from the corner of the mouth and posteriorly extending $1 \mathrm{~cm}$ from the pterygomandibular raphe. Superiorly the extent was for about $1 \mathrm{~cm}$ from the buccal vestibule (Figure 1). The swelling was soft but the contour was not smooth showing multiple demarcations. No thrill was palpated over the swelling. The swelling showed no changes in size during mouth opening. Under IV sedation patient underwent angiography via the femoral artery. The angiogram revealed no abnormal feeding vessels or draining veins (Figure 2). Faint opacification was seen in the venous phase in the region of the swelling. In view of no prominent feeder vessels, embolization was deferred. The lesion was treated by wide excision including the surrounding nidi (Figure 3), which was followed by reconstruction with buccal fat pad under general anaesthesia (Figure 4). Very minimal bleeding was note during the excision. On histopathological examination, the photomicrograph showed atrophic stratified parakeratinized squamous epithelium and collagenised stroma with numerous vascular channels 


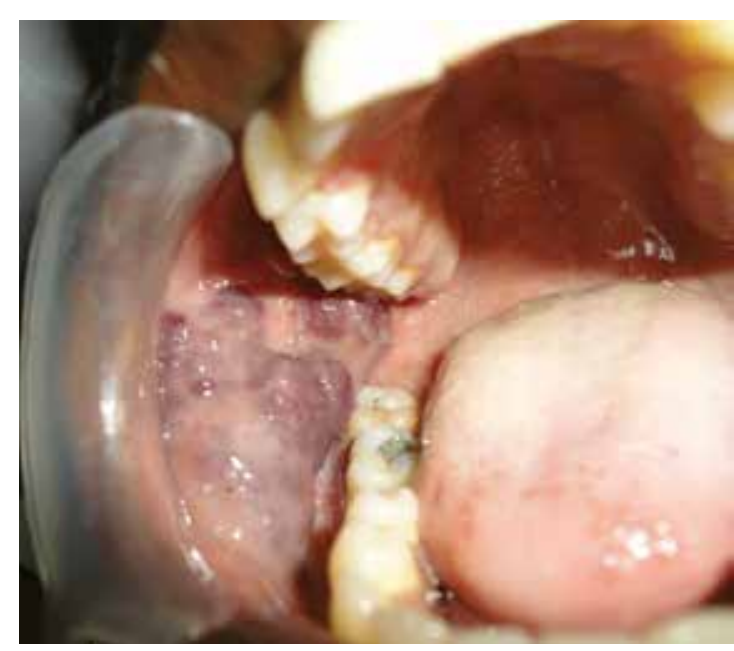

Figure 1 - Preoperative intraoral lesion

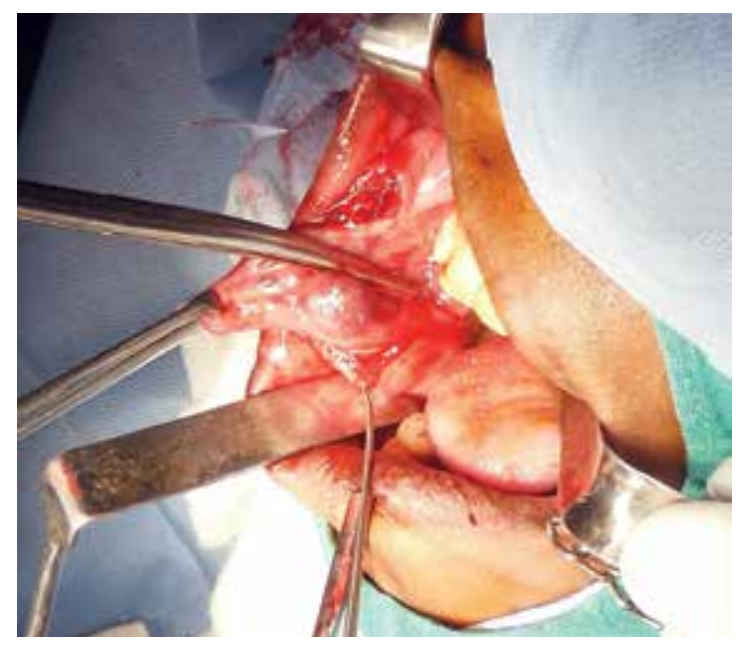

Figure 3 _ Surgical Excision

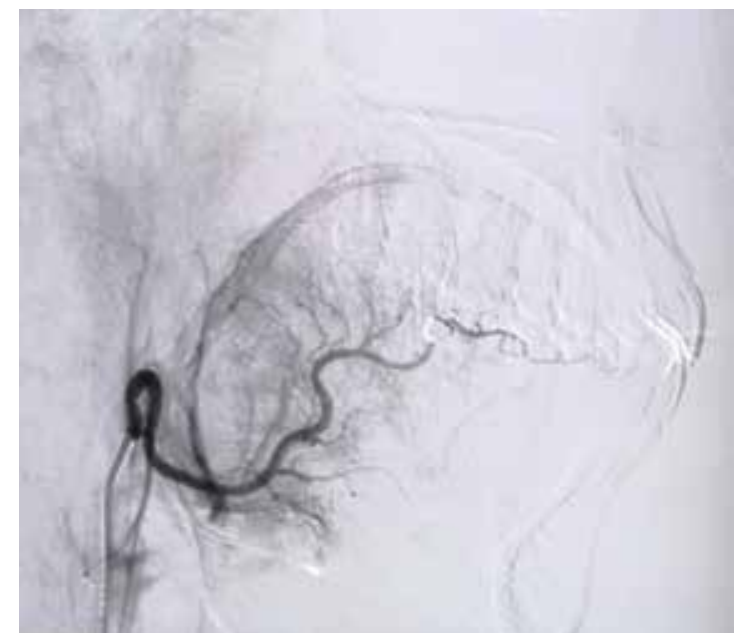

Figure 2 _ Angiography showing no feeder vessels

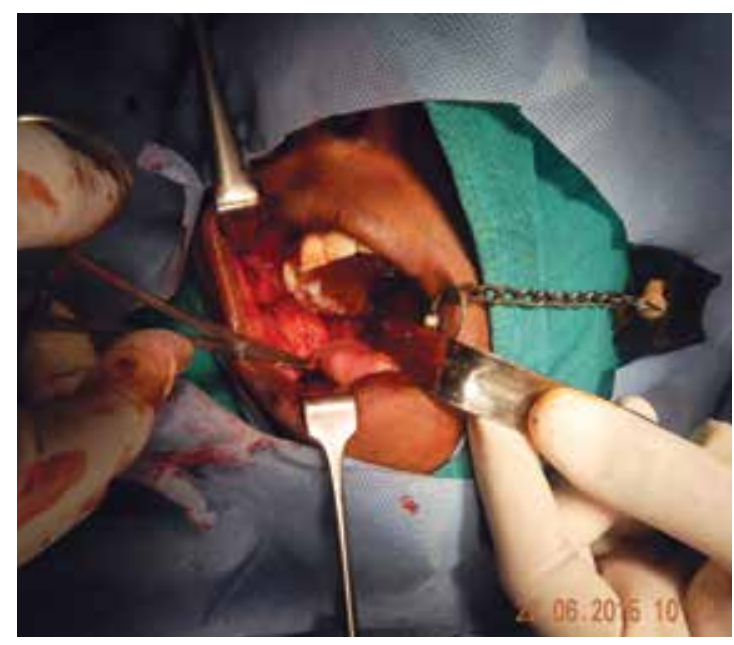

Figure 4 _ Buccal fat pad mobilized closure

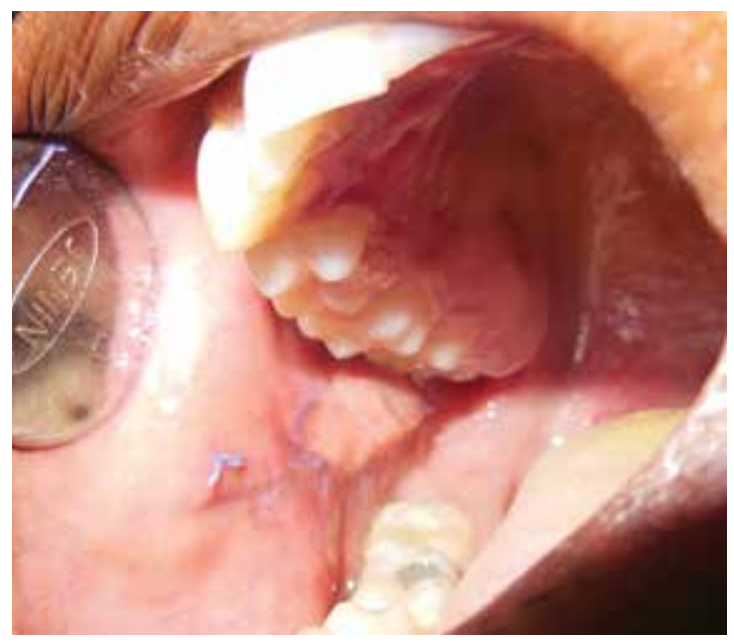

Figure 5 - 1 week Postoperative picture showing satisfactory healing 
of cavernous pattern. Abnormally dilated irregular channels with less well- formed vascular walls are also evident. Vascular channels insinuating muscle fibre bundles causing muscular atrophy and degeneration were also evident. The patient was followed up regularly and there was good take at recipient site and also there was no evidence of recurrence (Figure 5).

\section{Discussion:}

As reported in the literature venous malformations originate during embryonic development and hence should be present at birth. However consistent with the study done by Kohout MP ${ }^{[4]}$, in our case, the lesion was not evident at birth, but, rather noticed in adulthood. Patients with venous malformations first noticed during adulthood are often preceded by precipitating factors like trauma, hormonal changes like puberty. Necessary investigations to be done to assess the extent of venous malformation and its feeding vessels are very important. Preoperative embolization facilitates surgical excision which will be necessary to control intraoperative bleeding ${ }^{[4,5]}$. As there was no uptake of the dye by any of the feeder vessel we did not plan for embolization. Reconstruction of the defect followed by excision of the lesion should be done to restore form and function ${ }^{[6]}$. In our case the defect was reconstructed with buccal fat pad. Many sclerosing agents (sodium morrhuate, boiling water, nitrogen mustard, etc) are being used to treat high flow vascular lesions but they are not so effective as the agent is moved from the site of action due to blood flow ${ }^{[7]}$. Ligation of the external carotid artery is a promising adjunct but many authors don't accept it since many anastomoses (internal carotid, ophthalmic, vertebral, cervical and contralateral external carotid) create a rapid appearance of a collateral circulation ${ }^{[8]}$. Embolization combined with surgical excision is the treatment of choice ${ }^{[9]}$. This combined 98 approach controls the acute haemorrhagic phase, but doesn't reduce the recurrence rate because of emergence of collateral circulation ${ }^{[10]}$.

\section{Conclusion:}

The treatment of vascular head and neck lesions continues to evolve and with newer vascular radiologic techniques, embolic materials and surgical excision, patients get benefitted by the combined efforts of a surgeon and vascular radiologist. We conclude that Low flow venous malformations can be managed by surgical excision alone if there is no feeder vessel or very minimal uptake of the dye by a feeder vessel.

\section{Figure Legends}

Figure 1 - Preoperative intraoral lesion

Figure 2 - Angiography showing no feeder vessels

Figure 3 - Surgical Excision

Figure 4 - Buccal fat pad mobilized closure

Figure 5- 1 week Postoperative picture showing satisfactory healing

The authors have no potential conflicts of interest.

\section{References:}

1. Burrows PE, Laor $\mathrm{T}$, Palteil $\mathrm{H}$ et al: Diagnostic imaging in the evaluation of vascular birthmarks. Dermatol Clin 1998:16:455-458.

2. Mc Cafferry IJ, Jones RG. Imaging and management of vascular malformations. Clin Radiol 2011: 66:1208-1218.

3. Richter GT, Suen J, North PE, James CA et al. AV malformations of the tongue:a spectrum of disease. Laryngoscope 2007:117:328-35.

4. Kohout MP, Hansen M, Pribaz JJ et al. Arteriovenous malformations of the head and neck: natural history and management. Plast Reconstr Surg 1998:102:643-54.

5. Kim JY, Kim DI, Do YS, et al. Surgical treatment for congenital arteriovenous malformation: 10 years' experience. Eur J Vasc Endovasc Surg 2006:32:101-6.

6. Hartzell LD, Stack Jr BC, Yuen J, et al. Free tissue reconstruction following excision of head and neck arteriovenous malformations. Arch Facial Plas Surg 2009:11:171-7.

7. Kula K, Blakey G, Wright JT et al. High flow vascular malformations: literature review and case report. Pediatr Dent 1996:18:322-7.

8. Mulliken JB, Glowacki J. Hemangiomas and vascular malformations in infants and children: a classification based on endothelial characteristics. Plast Reconstr Surg 1984: 69: 412-22.

9. Mohammadi H, Said-al-Naief NA, Heffez LB. Arteriovenous malformation of the mandible. Report of a case with a note on th edifferential diagnosis. Oral surg oral med oral pathol oral radiol endod 1997:4:286-9 
10. Abouzgia MB, Symington JM. Recurrent arteiovenous malformation of the mandible: a case report J Oral Maxillofac Surg 1992:50:1230-3.

\section{Address of Correspondence}

V.Venugopalan

No.1, a-cross, 12th street, Krishna nagar,

Pondicherry - 605008.

Cell : 9500461241

abilashv3@gmail.com

\section{Authors:}

${ }^{1}$ Professor \& Head, Oral and maxillofacial surgery, Indira Gandhi Institute of Dental Sciences, Pondicherry

${ }^{2}$ Professor, Oral and maxillofacial surgery, Indira Gandhi Institute of Dental Sciences, Pondicherry

${ }^{3,4}$ Postgraduate student, Oral and maxillofacial surgery,Indira Gandhi Institute of Dental Sciences, Pondicherry

\section{How to cite this article :}

Sathyanarayanan .R, Suresh.V, Venugopalan .V, Deepika .S. Low Flow Venous Malformation of the Buccal Mucosa Treated by Surgical Excision - A Rare Case Report. Journal of Scientific Dentistry, 2017;7(1):42-45

Source of Support : Nil, Conflicts of Interest : None declared 